\title{
FAR FIELD MEASUREMENTS OF PhC LED PREPARED BY E-BEAM LITHOGRAPHY
}

\author{
Pavol Hronec $^{*}$ — Jaroslava Škriniarová ${ }^{*}$ - Anna Benčurová ${ }^{* * *}$ \\ Pavol Nemec $^{* * *}$ — Dušan Pudiš ${ }^{* *}$ _ Jaroslav Kováč
}

\begin{abstract}
The paper deals with optical characterization of the $\mathrm{Al}_{0.295} \mathrm{Ga}_{0.705} \mathrm{As} / \mathrm{GaAs}$ multi-quantum well light emitting diode (LED) structure with photonic crystal (2D PhC) patterned on the top of the structure using Electron Beam Direct Write Lithography (EBDWL). Light-current characteristics measured by integrating sphere shows increase of extracted light intensity as $21.1 \%$. Additionally, extracted light intensity was studied by far-field measurements as a complementary method to light-current characteristics. The far-field measurements show increase of extracted light intensity as $31.2 \%$. We suggest this method as more suitable for evaluation of extracted light intensity because it omits emission from edges of the LED and thus light is measured only from the area where $\mathrm{PhC}$ is patterned.
\end{abstract}

K e y w o r d s: LED, Electron beam direct write lithography, photonic crystal, far field, light extraction

\section{INTRODUCTION}

Since the first light emitting diode (LED) was created, there is a worldwide effort to constantly improve its optical power output and thus improving extracted light intensity because a high fraction of the generated light is back reflected due to a total internal reflection at semiconductor-air interface. For this purpose, currently is very widely used approach based on using photonic crystals $(\mathrm{PhC})$ on the top or buried in the LED structure $[1,2]$. To quantify improvement of the LED optical properties, there are needed optical characterization methods such as light-current measurements, near- [3] and far-field measurements. Far-field intensity distribution of PhC LEDs was studied in $[4,5]$ where distribution of emitted light and photonic crystal properties were primarily investigated. However, also extracted light intensity increase can be determined from far-field measurements. This approach is presented in this paper and can be effectively used especially for PhC LEDs.

\section{THEORY}

LED far-field measurements were performed as a relative light intensity distribution in spherical coordinate system $(\phi, \theta, r)$. To determine the effect of $\mathrm{PhC}$ on farfield pattern of LEDs as well as extracted light intensity increase, the following steps were needed:

(i) transformation of the measured data into the Cartesian coordinate system, (ii) interpolation using Thin plate spline interpolating method [6].

(iii) (iii) far-field distribution volume integration, which gives the relative output power of the LEDs.

\section{EXPERIMENT}

The patterned $\mathrm{Al}_{0.295} \mathrm{Ga}_{0.705} \mathrm{As} / \mathrm{GaAs}$ LED structure consists of $\mathrm{Al}_{0.295} \mathrm{Ga}_{0.705} \mathrm{As}$ active region with three GaAs quantum wells. The emitted central wavelength of the LED is at $845 \mathrm{~nm}$. Two-dimensional (2D) PhC with pillars was patterned using Electron Beam Direct Write Lithography (EBDWL). For our purpose the XR 1541006 e-beam patternable resists was chosen for its suitable resistance in the RIE etching and at the same time for its high pattern resolution.

The fabrication of LED with $\mathrm{PhC}$ structure (Fig. 1) consisted of a whole series of technological operations, such as: cleaning of the sample surface, photolithography, metallization, wet chemical etching. The following processing steps were employed for the realization of the device structures: upper ring metallization (p-type ohmic contact); bottom metallization (n-type ohmic contact); contacts annealing, and MESA etching.

The aim of the experiment was to determine how $\mathrm{PhC}$ patterned on the top of the LED structure affects light extraction from the structure surface. Structure without $\mathrm{PhC}$ was used as a reference structure and optical measurements were performed by two methods.

\footnotetext{
* Institute of Electronics and Photonics, Faculty of Electrical Engineering and Information Technology, Slovak University of Technology in Bratislava, Ilkovičova 3, 81219 Bratislava, Slovakia, pavol.hronec@stuba.sk; ${ }^{* *}$ Dept. of Physics, Faculty of Electrical Engineering, University of Žilina, Univerzitná 1, 01026 Žilina, Slovakia, ${ }^{* * *}$ Institute of Informatics, Slovak Academy of Sciences, Dúbravská cesta 9 , 84507 Bratislava, Slovakia,
} 


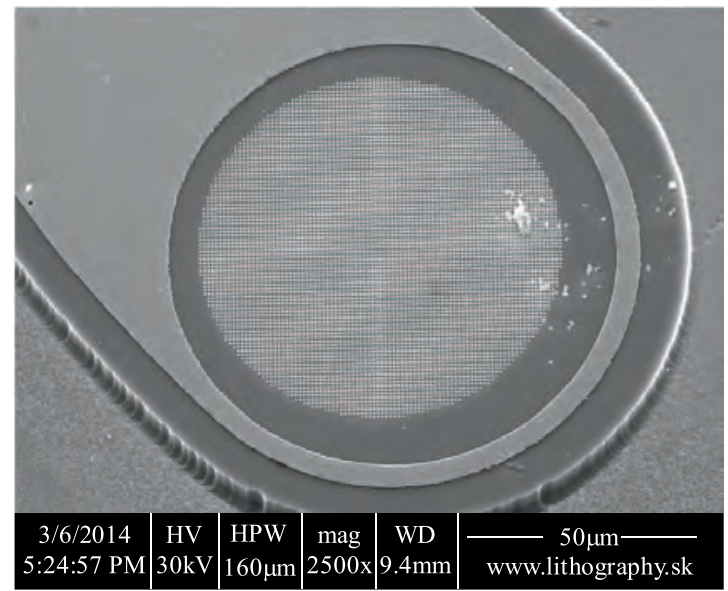

Fig. 1. SEM image of the investigated LED with patterned $\mathrm{PhC}$

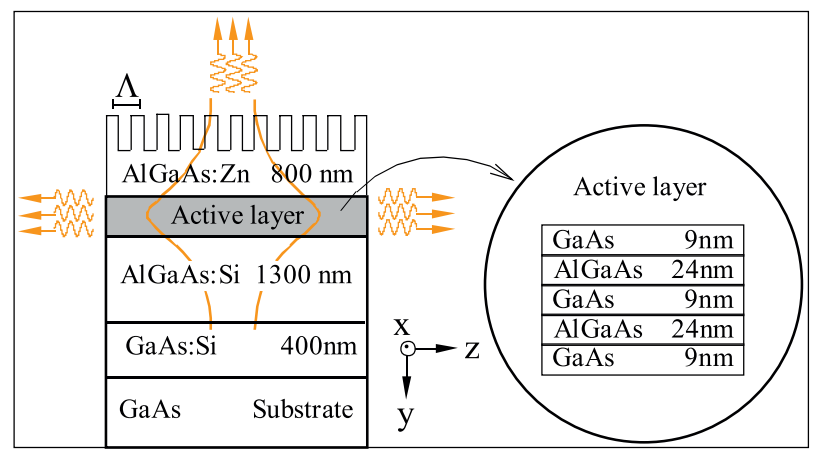

Fig. 2. AlGaAs/GaAs LED structure

The first one was the standard light-current measurement using current source from semiconductor parameter analyzer Agilent 4155C and universal optical power meter with integrating sphere Melles Griot 13 PDC 001. Since the investigated structure is composed of active layer with quantum wells, these act as a planar waveguide. In such a structure active layer can be approximated by the effective refractive index, which is higher than refracting index of boundary layers. [7-9] Thus, structure emits light from the top of the structure as well as from its edges due to generated guided modes, Fig. 2.

Light-current measurement includes both the light emitted from the LED surface and those emitted from the edges. For investigations of the $\mathrm{PhC}$ influence on the LEDs light extraction from the surface we proposed the second method based on measuring far-field intensity distributions of LEDs.

The far-field patterns were measured at $10 \mathrm{~mA}$ forward current by motorized precision rotation stage Thorlabs PRM1/MZ8E, photodiode, and lock-in amplifier Stanford Research Systems SR830. As a result, relative light intensity distributed in spherical coordinate system is measured. This measurement is then transformed to Cartesian coordinate system and plane defined by mea- sured points is interpolated using Thin Plate Spline 2D interpolation method. The relative integrated light intensity is then calculated as a volume integral under the interpolated plane.

The near-field patterns were measured by COHU 4910 camera. As a result, an 8-bit gray-scaled image is measured, where the relative optical output is distributed in pixels in two dimensions. Image processing is required to evaluate the measurements by integrating over all image pixels. Each pixel has a grey-scale value coded in 8 bits, which gives a value range of 0 to 255 . The total relative optical output in arbitrary units can be expressed as

$$
L=\sum_{j=1}^{N} \sum_{i=1}^{M} L_{i j}
$$

where $M \times N$ is image resolution, $i, j$ are numbers of pixels in both directions and $L_{i, j}$ is the relative optical output in a given pixel. Motivation for using these methods is to omit the light emitted from the edges of the $\mathrm{PhC}$ LED.

\section{RESULTS}

LED samples with 2D PhC structure was compared to the reference plane LED sample without PhC. PhC structures consist of 2-dimensional pillars with square symmetry and period of $500 \mathrm{~nm}$ as shown in Fig. 3. Height of the pillars was $\sim 350 \mathrm{~nm}$.

The optical properties of AlGaAs/GaAs MQW LED structure and its guided mode light extraction are described more detailed in [10]. Calculations showed that in such a structure there is one guided mode for TE and one for TM polarization with different penetration depths. As the most suitable $\mathrm{PhC}$ period for light extraction from studied AlGaAs/GaAs MQW LED structure was calculated period of $249 \mathrm{~nm}$. However, also second order of coupling grating can extract guided modes but with less efficiency. Extraction efficiency is also strongly dependent on $\mathrm{PhC}$ symmetry. For ideal light extraction 2D PhC should have circular irreducible Brillouin zone [10].

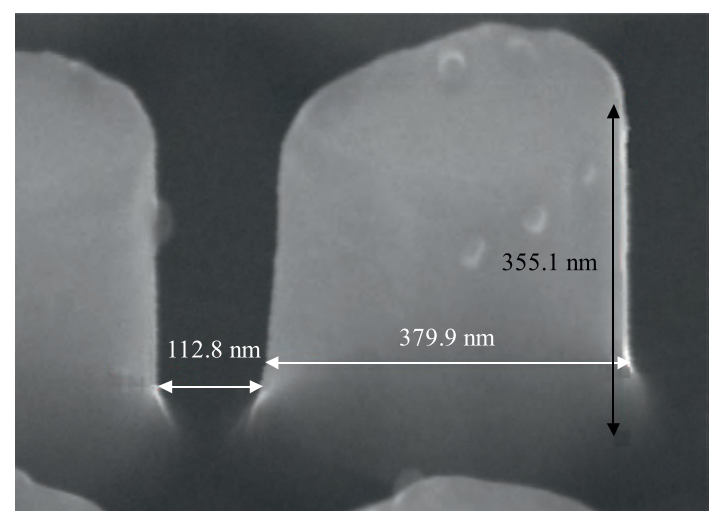

Fig. 3. SEM image of PhC patterned on the top of LED 


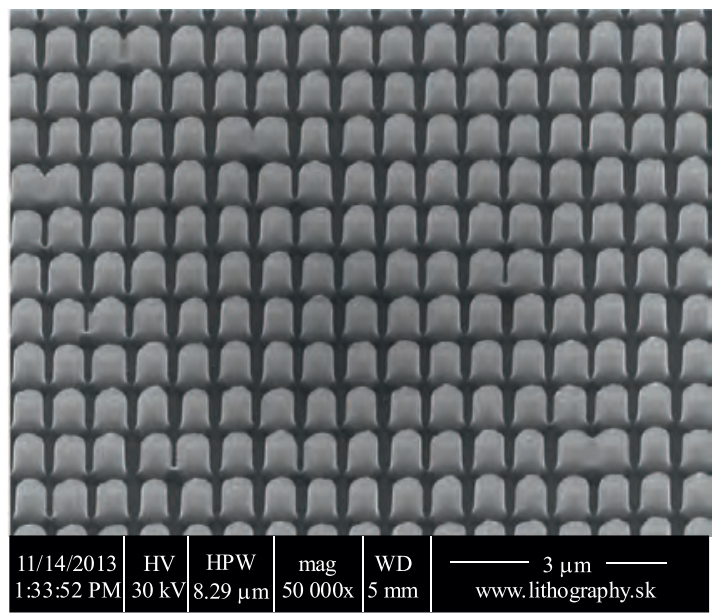

Fig. 4. Light-current characteristics of the reference LED without a PhC and of a2D PhC LED

The light-current measurements from Fig. 4 show comparison of light output power of reference and $2 \mathrm{D} \mathrm{PhC}$ LED in dependence of driving current. It was found that $\mathrm{PhC}$ on the top of the LED structure improves the extracted light intensity from LEDs. Extracted light intensity increase was evaluated at $10 \mathrm{~mA}$ forward current as $24.2 \%$. However, in comparison to light-current measurements, 2D PhC LED shows higher light extraction increase by using method of far-field LED light intensity distribution is shown in Fig. 5. The measurement range in Cartesian coordinate system represents range of $\pm 60^{\circ}$ in $\theta$ and $\phi$ coordinates of spherical coordinate system. The bottom far-field pattern represents reference LED, top far-field pattern represents $2 \mathrm{D} \mathrm{PhC}$ LED. The i ncrease in extracted light intensity increase of 2D PhC LED evaluated from volume integral of far-field pattern was $35.6 \%$.

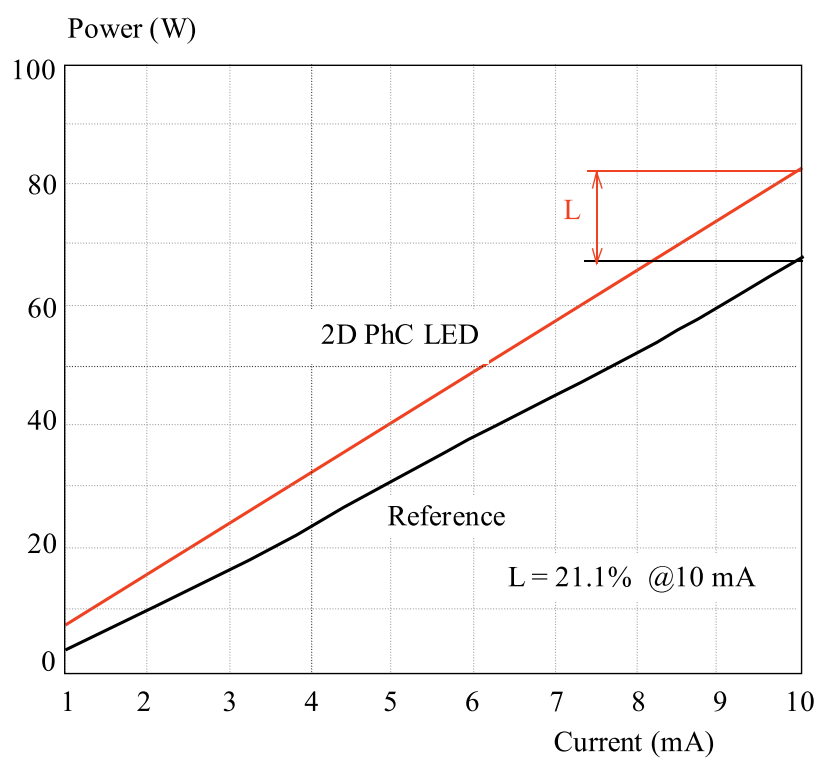

Fig. 6. Light-current characteristics of reference LED without 2D $\mathrm{PhC}$ and 2D PhC LED

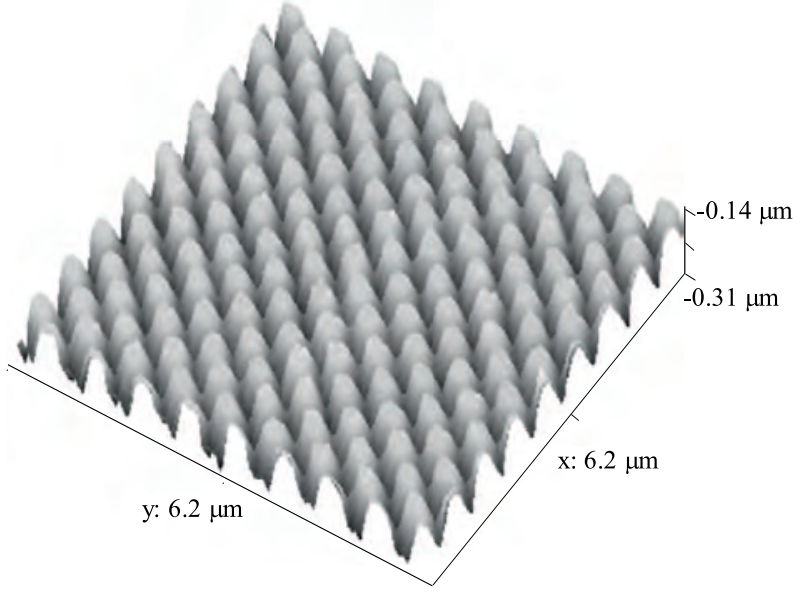

Fig. 5. Far field pattern for the reference LED (bottom, light colour) and for the 2D PhC LED (top, dark colour

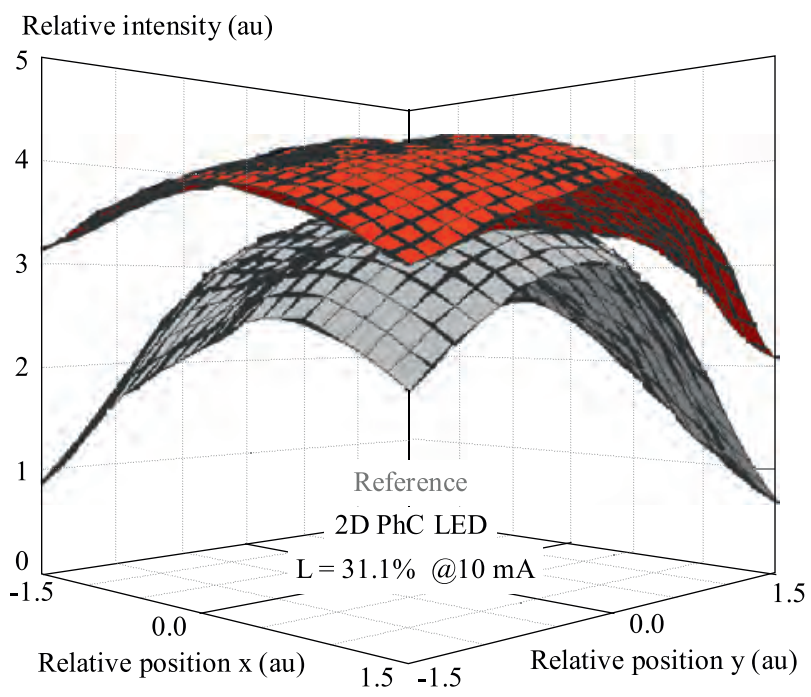

Fig. 7. Far field pattern for reference LED (bottom, light grey) and 2D PhC LED (top, dark grey)

Similar results like in far-field measurements were observed using the method of near-field measurements. Fig. 6 shows a comparison of light intensity in dependence on the driving current. $\mathrm{PhC}$ on the top of LED structure improves the light extraction of LEDs. The increase in the extracted light evaluated from near-filed measurements was $34.7 \%$. The higher light extraction improvement in the case of near- and far-field measurement in comparison with measurement by the integrating sphere was due to the fact that light emitted from the LED is measured only from the top of the structure and light emitted from the edges does not affect the measurement.

\section{CONCLUSIONS}

The extracted light intensity increase of a LED containing a $2 \mathrm{D} \mathrm{PhC}$ was investigated and compared with 
a reference LED without the $\mathrm{PhC}$ using three different methods. Besides conventional LED light-current measurement using an integrating sphere, two complementary methods were performed. The first one was far-field LED light intensity measurement performed at $10 \mathrm{~mA}$ of driving current. The second one was light-current measurement evaluated from near-field patterns at a driving current varying from 1 to $10 \mathrm{~mA}$. The results confirmed that the LED extracted light intensity increased when a $2 \mathrm{D} \mathrm{PhC}$ was patterned on the top of the LED structure. PhC light extraction enhancement was $24.2 \%$ using standard light-current measurements by the integrating sphere. Light extraction enhancement of $35.6 \%$ was achieved in the case of far-field measurement and $34.7 \%$ in the case of near-field measurement. These two methods show similar results because both collect only the light emitted from the top of the structure. In this case, unlike in measurements by the integrating sphere, edge emission does not affect the measurement. Therefore, we suggest these methods as more suitable for optical characterization of PhC LEDs.

\section{Acknowledgement}

We would like to thank to group of doc. Ing. Jozef Novák, DrSc. from Slovak Academy of Science for LED structure growth. This work was financially supported by project APVV-0395-12 and VEGA 1/0439/13.

This paper summarizes in brief the essential issues of a work presented at APCOM-2014, International Conference on Applied Physics of Condensed Matter, held at Štrbske Pleso, High Tatras, Slovakia, on 25-27 June 2014.

\section{REFERENCES}

[1] PUDIŠ, D.-ŠUŠLIK, L'--KUBICOVÁ, I.-ŠKRINIAROVÁ, J.-MARTINČEK, I. : Advanced Optical Methods for Patterning of Photonic Structures in Photoresist, III-V Semiconductors and PMMA, Proc. of SPIE 7746 (2010), 774616-1-6.

[2] KUBICOVÁ, I.-PUDIŠ, D.-ŠUŠLIK, L.-ŠSKRINIAROVÁ, J.-SLABEYCIUSOVÁ, S.-MARTINČEK, I. : Structures Patterning by Non-Contact NSOM Lithographyjour Proc. of SPIE.

[3] HRONEC, P.—KOVÁČ, J.-ŠKRINIAROVÁ, J.: Investigation of the LED with PhC Prepared by e-Beam Lithography, Proc. of ADEPT (2014), 27-30.

[4] CHUN-FEnG, L.-JIM-YONG, C.-HAO-CHUNG, K.-HSIHSUAN, Y.-CHIA-EN, L.-CHIA-HSIN, C.-WEN-YUNG, Y.-TIEN-CHANG, L.: Far-Field and Near-Field Distribution of GaN-Based Photonic Crystal LEDs with Guided Mode Extraction, IEEE Journal of Selected Topics in Quantum Electronics 15 No. 4 (2009), 1234-1241.

[5] CHUN-FENG, L.-JIM-YONG, C.-HAO-CHUNG, K.-HSIHSUAN, Y.-CHIA-EN, L.-CHIA-HSIN, C.-HAN-TSUNG, H.-WEN-YUNG, Y.: Far-Field of GaN Film-Transferred
Green Light-Emitting Diodes with Two Dimensional Photonic Crystals, Optics ExprESS 17 No. 11 (2009).

[6] BOOKSTEIN, F. L. : Principal Warps: Thin-Plate Splines and the Decomposition of Deformations, IEEE Transactions on Pattern Analysis and Machine Intelligence 11 No. 6 (1989), 567-585.

[7] Alman, G. M.-MOLTER, L. A.-SHEN, H.-DUTTA, M. : Refractive Index Approximations from Linear Perturbation Theory for Planar MQW Waveguides, IEEE Journal of Quantum Electronics 28 No. 3 (1992), 650-657.

[8] SAINI, M.-SHARMA, E. K.: Equivalent Refractive Index of MQW Waveguides, IEEE Journal of Quantum Electronics 32 No. 8 (1996), 1383-1390.

[9] SONEK, G. J.-BALLANTYNE, J. M.-CHEN, Y. J.-CARTER, G. M.-BROWN, S. W.-KOTELES, E. S.-SALERNO, J. P.: Dielectric Properties of GaAs/AlGaAs Multiple Quantum Well Waveguides, IEEE Journal of Quantum Electronics 22 No. 7 (1986), 1015-1018.

10] HRONEC, P.-KOVÁČ, J.: Guided Mode Light Extraction from LED Structure Using Photonic Crystals, Proc. of 14th Conference of Doctoral Students ELITECH' 12 Bratislava, Slovak Republic.

Received 15 July 2014

Pavol Hronec (Ing), born in Komárno, Czechoslovakia, in 1987, graduated from Faculty of Electrical Engineering and Information Technology, Slovak University of Technology, Bratislava, from Microelectronics, in 2011. He is currently $\mathrm{PhD}$ student at the Institute of Electronics and Photonics of Faculty of Electrical Engineering and Information Technology. His main activities are teaching and research in the area of electrical and optical characterization of light-emitting diodes as well as development of these characterization techniques.

Jaroslava Škriniarová (Ing, CSc) received her Ing (MSc) and CSc degree from the Slovak University of Technology (STU), Bratislava, in 1977 and 1986. In 1993 she joined the Microelectronics Department of STU, at present she is there engaged in the research of optoelectronic devices. Her scientific interests include chemical processing of semiconductor materials, thin films and surfaces.

Dušan Pudiš (doc, Ing, $\mathrm{PhD}$ ) received degrees from the Faculty of Electrical Engineering, Slovak University of Technology Bratislava, MSc (Ing) in 1997, PhD in 2001 and doc (Assoc. prof) in 2007, FEI STU. From 2002 he works in Physics Department in University of Žilina in the field of semiconductor devices and photonic structures.

Jaroslav Kováč (Prof, Ing, PhD) was born in Tornala, Slovakia, in 1947. He graduated from the Slovak University of Technology, Faculty of Electrical Engineering and Information Technology (FEI STU), Bratislava, in 1970. Since 1971 he has been engaged in the research of optoelectronic devices technology at the Microelectronics Department of FEI STU. He received a $\mathrm{PhD}$ degree (1983) and professor degree (2001) at STU Bratislava. Since 1991 he has been the team leader of the Optoelectronic group at the Institute of Electronics and Photonics. 